David R. Gambling MB BS DRCOG FRCPC, Christopher J. Huber MD FFARCS FRCPC, Johnathan Berkowitz PhD, ${ }^{*}$

Paul Howell BSc MB BChB FFarCS, Jean E. Swenerton MD FRCPC, Peggy L.E. Ross BScM MD FRCPC, Chantal $T$. Crochetière MD FRCPC, Timothy J.G. Pavy MB BS FFARACS FFARCS

\title{
Patient-controlled epidural analgesia in labour: varying bolus dose and lockout interval
}

This double-blind prospective study was designed to determine the best dose variables for patient-controlled epidural analgesia (PCEA) and to compare bolus-only PCEA with continuous infusion epidural analgesia (CIEA) during the first stage of labour. Five groups of parturients self-administered $0.125 \%$ bupivacaine with 1:400,000 epinephrine and fentanyl $2.5 \mu \mathrm{g} \cdot \mathrm{ml}^{-1}$ using PCA pumps programmed as follows: Group A, $2 \mathrm{ml}$ bolus/10 min lockout interval (LI); Group B, $3 \mathrm{ml}$ bolus/15 min LI; Group C, $4 \mathrm{ml}$ bolus $/ 20 \mathrm{~min} \mathrm{LI;} \mathrm{Group} \mathrm{D,} 6 \mathrm{ml}$ bolus/30 min LI; Group $E, 8 \mathrm{ml} \cdot \mathrm{hr}^{-1}$ continuous infusion. Hourly assessments included: VAS scores for pain and satisfaction, sensory and motor block, bupivacaine and fentanyl consumption. Blood samples were collected at birth for maternal and fetal fentanyl concentrations. Data from 68 patients showed no differences among groups in pain relief or maternal satisfaction. Most patients received excellent analgesia and those requiring extra epidural supplements were evenly distributed across groups. There was higher consumption of bupivacaine and fentanyl in Group $E$ than in any of the other four groups:

\section{Key words}

ANAESTHESIA: obstetric;

ANAESTHETIC TECHNIQUES: epidural;

ANAESTHETICS LOCAL: bupivacaine;

ANALGESICS: fentanyl;

EQUIPMENT: patient-controlled analgesia.

From the Division of Obstetric Anaesthesia, University of

British Columbia and Grace Hospital, Vancouver, B.C.

Canada. (*Berkowitz and Associates, statistical and

mathematical consultants).

Supported in part by a grant from Bard, Canada.

Presented at the Annual Meeting of the American Society

of Regional Anesthesia, Cincinnati, OH, April 1991.

Address correspondence to: Dr. David R. Gambling,

Division of Obstetric Anesthesia, Department of

Anesthesiology and Pain Management, University of Texas,

Southwestern Medical Center, 5323 Harry Hines Blvd, Dallas,

Texas 75235-9068 U.S.A.

Accepted for publication 9th November, 1992. bupivacaine $m g \cdot h r^{-1}$, mean (SD), 9.4 (2.7) in Group $E$ vs 5.2 (1.7) in Groups $A-D$ inclusive ( $P<0.0001$ ); fentanyl $\mu \mathrm{g} \cdot \mathrm{hr}^{-1}$, 19.6 (4.6) in Group E vs 12.6 (7.5) in Groups $A-D$ inclusive $(P<0.05)$. Motor block was minimal, whereas sensory levels were higher at the 3- and 4-hour assessments in Groups $D$ and $E$ than in all other groups $(P<0.05)$. Plasma fentanyl concentrations were $<0.5 \mathrm{ng} \cdot \mathrm{ml}^{-1}$ in all samples and no sequelae from fentanyl were observed, apart from mild pruritus. Bolus-only PCEA is a safe and effective alternative to CIEA during the first stage of labour irrespective of the initial dose variables selected.

Cette étude à double insu vise à déterminer les meilleures variables posologiques pour l'anesthésie épidurale autocontrôlée (PCEA) et d'établir la comparaison de la PCEA à bolus avec une perfusion épidurale continue pendant le premier stage du travail. Cinq groupes de parturientes se sont administrées ellesmêmes de la bupivacaine 0,125 avec épinéphrine 1:400 000 et du fentanyl 2,5 $\mu \mathrm{g} \cdot \mathrm{kg}^{-1}$ avec des injecteurs PCA programmés de la façon suivante: groupe $A, 2 \mathrm{ml}$ en bolus avec $10 \mathrm{~min}$ dintervalle de sécurité (IS); groupe $B, 3 \mathrm{ml}$ en bolus $15 \mathrm{~min}$ $I S$; groupe $C, 4 \mathrm{ml}$ en bolus $20 \mathrm{~min} I S$; groupe $D, 6 \mathrm{ml}$ en bolus 30 min IS; groupe $E, 8 \mathrm{ml}^{-1}$ en perfusion continue. L'évaluation horaire comprend: les scores EVA pour la douleur et la satisfaction; lévaluation des blocs sensitif et moteur, la consommation de bupivacaine et de fentanyl. Des échantillons de sang sont prélevés à la naissance pour déterminer les concentrations maternelles et foetales de fentanyl. Les données recueillies chez 68 parturientes ne montrent pas de différences intergroupes en ce qui concerne le soulangement de la douleur et la satisfaction. La plupart des patientes ont obtenu une excellente analgésie et celles qui ont eu besoin de supplémentation épidurale se sont distribuées également entre les groupes. La consommation de fentanyl et de bupivacaine a été plus importante dans le groupe $E$ que dans chacun des groupes: bupivacaine $\mathrm{mg} \cdot \mathrm{kg}^{-1}$, moyenne (ET), 9,4 (2,7) dans le groupe $E$ vs $5,2(1,7)$ dans les groupes $A-D(P<0,0001)$; fentanyl $\mu \mathrm{g} \cdot h \mathrm{r}^{-1}, 19,6(4,6)$ dans le groupe $E$ vs $12,6(7,5)$ dans les groupes $A-D(P<0,05)$. Le bloc moteur été négligeable alors que les niveaux sensitifs ont été plus élevés à troisième et la 
quatrième heure dans les groupes $D$ et $E$ que dans tous les autres groupes $(P<0,05)$. Les concentrations plasmatiques ont été inférieures à $<0,5 \mathrm{ng} \cdot \mathrm{ml}^{-1}$ dans tous les échantillons et aucune séquelle attribuable au fentanyl nëté notée à l'exception d'un léger prurit. La technique du PCEA à bolus seuls est une alternative sécuritaire et efficace à la CIEA pendant le premier stage du travail indépendamment des variables posologiques initiales.

When we lose control over our environment and our body, pain tolerance and perception are adversely affected. ${ }^{1}$ In hospital, parturients experience a loss of control, to some extent, in privacy, mobility, bodily functions and choice. With the advent of patient-controlled analgesia (PCA), some control has been returned to patients which has increased their satisfaction with pain relief. Previous studies have shown that application of PCA to epidural analgesia in labour allows parturients to titrate adequate and satisfactory analgesic levels on demand. . $^{2-6,8-11}$ Dosing delays are avoided which decreases the feed-back loop. Self-administration of small increments of dilute local anaesthetic is more likely to avoid the adverse consequences of large bolus administration.

Patient-controlled epidural analgesia (PCEA) is versatile, effective and associated with high patient satisfaction. ${ }^{2,6,10}$ In addition, it is safe and is associated with lower local anaesthetic requirements than continuous infusion epidural analgesia (CIEA). ${ }^{2,4}$ The efficacy of PCEA is due to prompt administration of drug and the alleviation of anxiety often associated with the anticipation of a return of pain. The concept of patient-control is easily understood and well accepted by most parturients.

To date, dosing variables for PCEA have been arbitrarily selected. This study was designed to determine the optimal initial combination of bolus dose and lockout interval. It was decided that any dose combination would be deemed superior if associated with greater analgesia, improved patient satisfaction, lower sensory levels or a success: total PCA demand ratio close to 1.0. At the same time, bolus-only PCEA was compared in a double-blind fashion with CIEA.

\section{Methods}

The study was approved by the hospital and university research committees. Informed consent was obtained from each parturient. Nulliparous, ASA I or II, Englishspeaking parturients with uncomplicated, singleton pregnancies, $18 \mathrm{yr}$ or more, in established labour and requesting epidural analgesia were recruited. Women with severe medical or obstetric complications, multiple gestation, contraindication to epidural analgesia, local anaesthetic or fentanyl allergy, were excluded from the study.
TABLE I Study groups

\begin{tabular}{ll}
\hline Group A & $2 \mathrm{ml}$ bolus $/ 10$ min lockout \\
Group B & $3 \mathrm{ml}$ bolus $/ 15 \mathrm{~min}$ lockout \\
Group C & $4 \mathrm{ml}$ bolus $/ 20$ min lockout \\
Group D & $6 \mathrm{ml}$ bolus $/ 30$ min lockout \\
Group E & $8 \mathrm{ml} / \mathrm{hr}$ continuous infusion \\
\hline
\end{tabular}

Analgesic mixture for each group was: bupivacaine $0.125 \%+$ $1: 400,000$ epinephrine + fentanyl $2.5 \mu \mathrm{g} \cdot \mathrm{ml}^{-1}$.

Each parturient received $500-1000 \mathrm{ml} \mathrm{NaCl} 0.9 \%$ iv prior to initiating epidural blockade. Epidural catheter placement was performed in a standard manner and all patients were given an initial dose of $8-10 \mathrm{ml}$ bupivacaine $0.25 \%$.

Patients were instructed in the use of the Bard PCA ${ }^{\circledR}$ pump and then randomly assigned to one of five groups (Table I). Each group received bupivacaine $0.125 \%$ with 1:400,000 epinephrine and fentanyl $2.5 \mu \mathrm{g} \cdot \mathrm{ml}^{-1}$ through the pump.

An infusion rate of $8 \mathrm{ml} \cdot \mathrm{hr}^{-1}$ was selected for CIEA (Group E) because it is an infusion rate commonly used in our institution. The PCA demand button was used, but made inactive for these patients. The study protocol allowed for changing the infusion rate in order to maintain the sensory level between $T_{10}$ and $T_{6}$.

Both patient and investigator were unaware of the group assignment. The PCA pump was programmed by a second investigator after referring to a previously constructed randomisation table. All patients, including those in Group E, were told to press the demand button when pain returned and to expect some relief within five to ten minutes. Supplemental epidural analgesia was provided if patients failed to get adequate pain relief after 30 min despite making numerous demands in that time. Additional boluses of bupivacaine $(0.125-0.5 \%)$ were used to overcome inadequate sensory levels and fentanyl $(25-100 \mu \mathrm{g})$ was given for back pain and/or perineal discomfort, in the presence of bilateral $\mathrm{T}_{10}$ sensory levels. If these supplements were inadequate a full "top-up" dose of $12 \mathrm{ml}$ bupivacaine $0.125 \%$ with $1: 800,000$ epinephrine was injected. If this was unsuccessful the patient was removed from the study.

The study began when the PCA pump was attached to the epidural catheter and ended with the onset of the second stage. Every hour, a blinded investigator collected the following data: $10 \mathrm{~cm}$ VAS scores for pain, satisfaction, maximum pain/minimum satisfaction in the preceding hour, sensory levels (using ice), motor block, maternal BP and fetal heart rate (FHR). Other data included hourly bupivacaine and fentanyl requirements including all supplements but excluding the initial dose of bupivacaine $0.25 \%$; the ratio of successful to total PCA demands; duration and outcome of labour; one and five 
TABLE II Demographic data, (mean \pm SD)

\begin{tabular}{lllllll}
\hline Group & $\begin{array}{l}A \\
(n=14)\end{array}$ & $\begin{array}{l}B \\
(n=14)\end{array}$ & $\begin{array}{l}C \\
(n=13)\end{array}$ & $\begin{array}{l}D \\
(n=14)\end{array}$ & $\begin{array}{l}E \\
(n=13)\end{array}$ & $\begin{array}{l}P \text { value } \\
\text { ANOVA }\end{array}$ \\
\hline Age (yr) & $29.5 \pm 4.86$ & $28.3 \pm 4.32$ & $29.7 \pm 4.8$ & $28.8 \pm 5.84$ & $28.1 \pm 3.66$ & 0.87 \\
Height $(\mathrm{cm})$ & $164.25 \pm 9.04$ & $164.25 \pm 8.18$ & $163.44 \pm 5.98$ & $163.71 \pm 5.54$ & $160.23 \pm 9.36$ & 0.65 \\
Weight $(\mathrm{kg})$ & $78.0 \pm 14.0$ & $75.3 \pm 10.9$ & $66.7 \pm 8.9$ & $79.5 \pm 15.9$ & $75.1 \pm 11.8$ & 0.09 \\
Study length (hrs) & $6.6 \pm 2.6$ & $7.1 \pm 3.5$ & $5.0 \pm 2.2$ & $6.7 \pm 3.0$ & $7.5 \pm 5.2$ & 0.39 \\
Cx DIL at start of study (cm) & $3.6 \pm 1.5$ & $3.6 \pm 1.6$ & $2.9 \pm 1.0$ & $3.3 \pm 1.0$ & $3.6 \pm 1.2$ & 0.60 \\
\hline
\end{tabular}

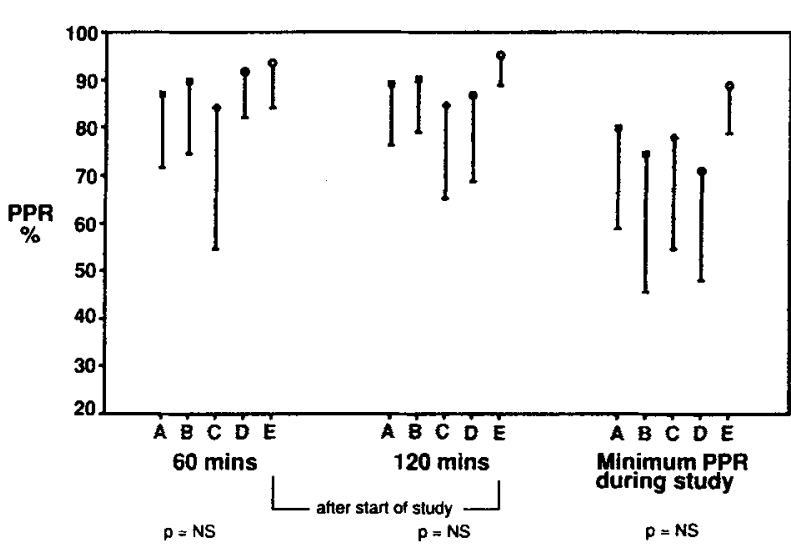

FIGURE 1(a) Pain relief index (PPR) mean $\pm S D$.

min Apgar scores; and a global evaluation of analgesia and satisfaction by patient and investigator following completion of the study.

All VAS levels were converted into pain relief and satisfaction indices which represented a $\%$ change from the baseline score. Percentage pain relief (PPR) is 100 minus [(measured VAS $\div$ pre-epidural VAS $) \times 100]$. A high PPR represents excellent analgesia, while a low PPR represents inadequate analgesia. This applies equally to satisfaction score (SS).

Plasma fentanyl concentrations were measured on maternal venous and umbilical artery samples taken at delivery. An enzyme-linked immunoabsorbent assay (ELISA) was performed using a kit produced by Kentucky Technology Inc, at the CanTest laboratories in Vancouver. This assay measured concentrations of fentanyl and its metabolite. Average absorbency was plotted against fentanyl concentration with a correlation coefficient equal to 0.99 .

Statistical analysis of data was performed using Chisquare analysis, a series of one-way analyses of variance to compare all groups at each time and repeated measures analysis of variance to consider all time points in a single analysis. Demographic data were compared using oneway analysis of variance. Total analgesic supplements across groups were compared using Chi-square goodness

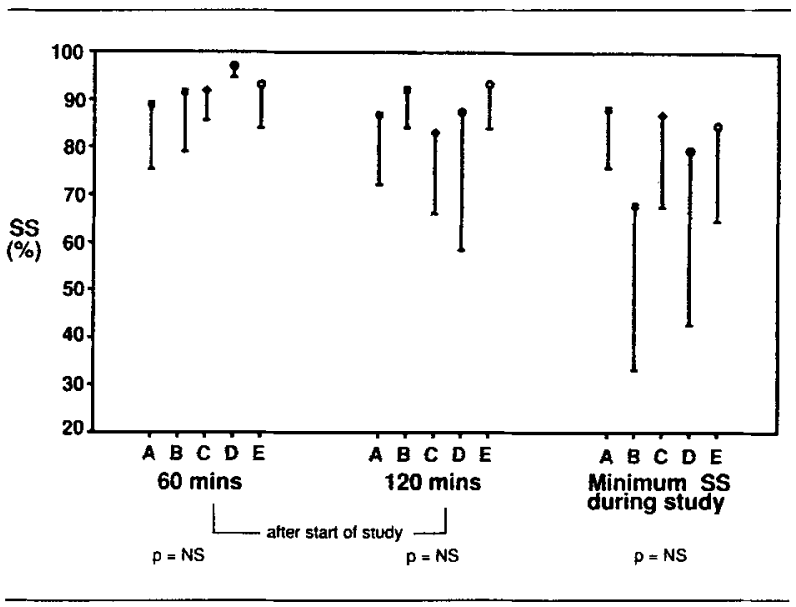

FIGURE 1(b) Satisfaction score (SS) mean \pm SD.

of fit tests. A $P$-value $<0.05$ was considered to be statistically significant.

All groups were compared independently but for the purposes of comparing PCEA with CIEA, data from groups A-D inclusive were also compared with Group E alone. Our sample sizes gave $80 \%$ power with 15 patients in each group in order to detect changes of the following magnitudes: a difference in VAS score of 2 (with a SD of 2) between two groups; a 2-segment difference in sensory level; a difference of 0.3 in PCA (success:total) demand ratio. These values were chosen in order to detect what would, in our opinion, be clinically important differences.

\section{Results}

Seventy-five patients were recruited to the study but data from only 68 were analysed. Four patients were excluded because of incomplete data; one had a blocked epidural catheter; one had inadequate analgesia from the initial dose and the last was withdrawn at her own request after she had failed to use the pump as instructed.

All five groups consisted of patients similar in terms of age, height, weight, study duration and cervical dilatation prior to epidural insertion (Table II).

There were no differences among groups in terms of pain relief or patient satisfaction throughout the study. 


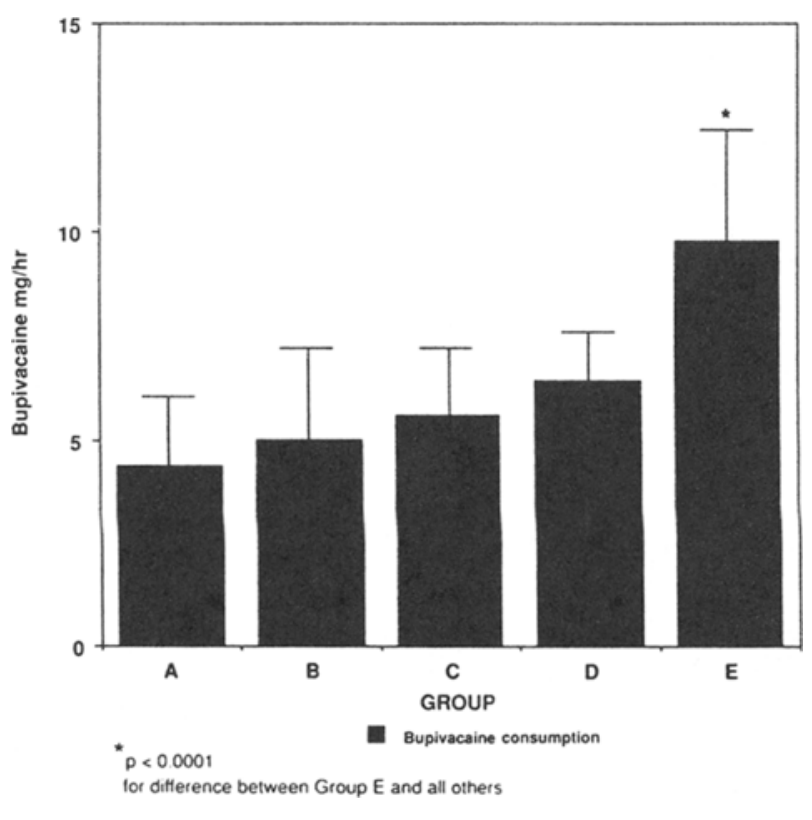

FIGURE 2(a) Bupivacaine consumption (mean \pm SD).

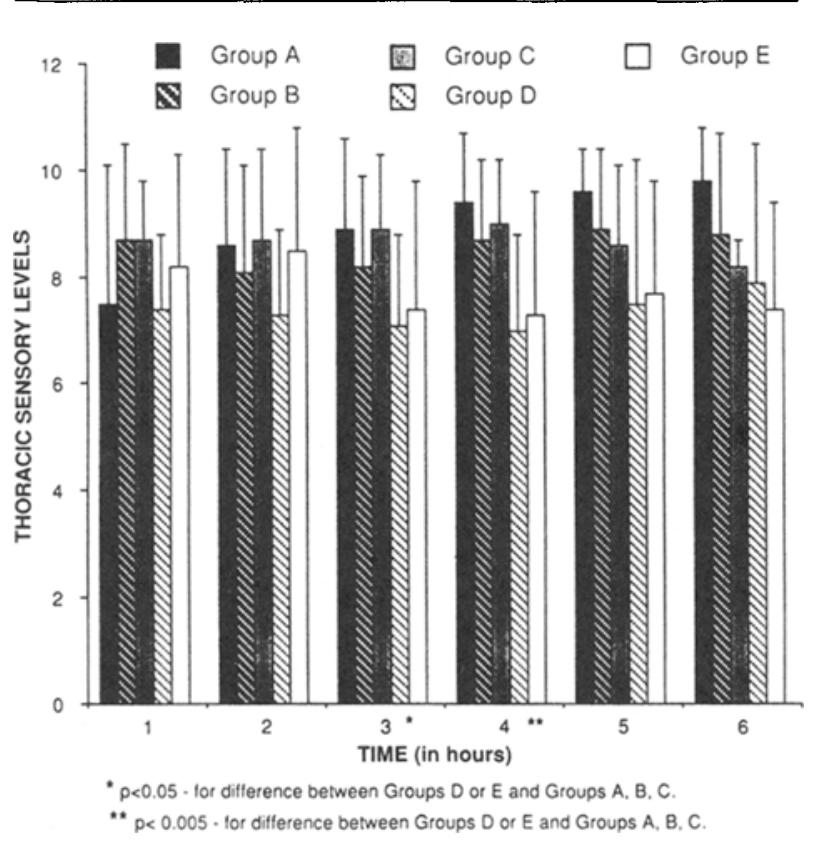

FIGURE 3 Sensory levels (mean + SD).

Figures $1 \mathrm{a}$ and $\mathrm{lb}$ abbreviate these results by showing PPR and SS at three assessment times only, but each is representative of all the other time comparisons.

Bupivacaine and fentanyl consumption were less in Groups A-D inclusive than in Group E, whether compared individually or combined (Figures $2 a$ and $2 b$ ).

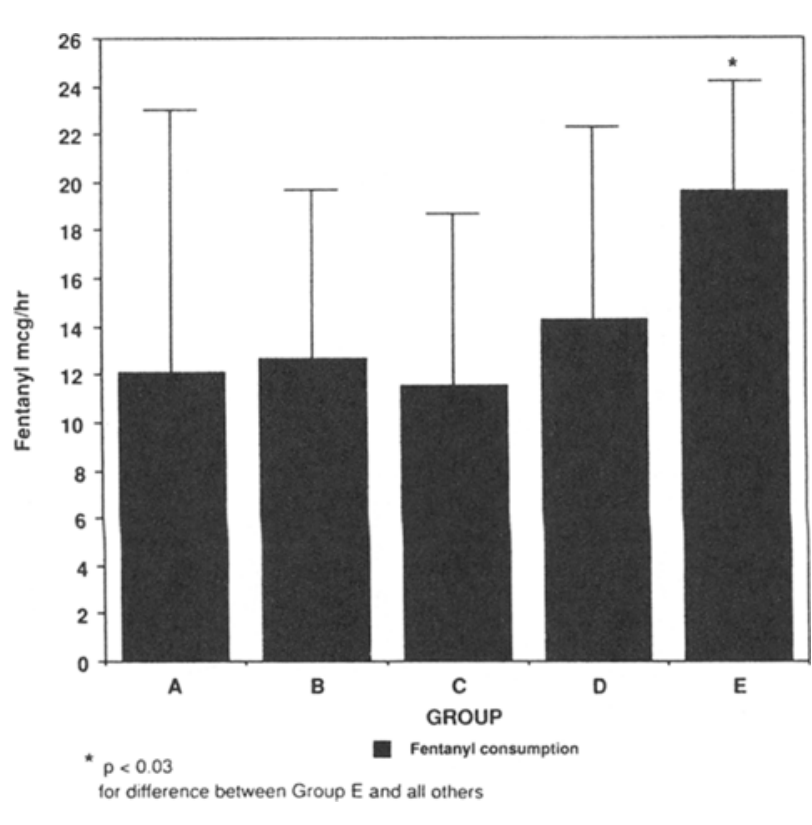

FIGURE 2(b) Fentanyl consumption (mean \pm SD).

There were no differences among any of the PCEA groups in this regard. In Group E, bupivacaine consumption, mean (SD), was $9.4(2.7)$ vs $5.2(1.7) \mathrm{mg} \cdot \mathrm{hr}^{-1}$ for Groups A-D combined, $P<0.0001$.

In Group E, fentanyl consumption was $19.6(4.6)$ vs $12.6(7.5) \mu \mathrm{g} \cdot \mathrm{hr}^{-1}$ for Groups A-D combined; $\mathrm{P}<0.05$.

Sensory levels were similar among groups, except at the third and fourth hourly intervals, where higher levels were seen in both Groups D and E than in all other groups (Figure 3).

Motor block was minimal in all patients, with no differences among groups (Table III).

There was no maternal hypotension or fetal bradycardia associated with PCA use.

All four PCEA groups (A-D) had similar ratios of successful:total PCA demands; range (mean $\pm \mathrm{SD}$ ) $=$ $0.41 \pm 0.26$ to $0.63 \pm 0.22$.

There were no differences among groups in terms of the number of bupivacaine or fentanyl epidural supplements for inadequate analgesia (Table IVa and b). Seventy-five percent of those patients requiring a supplement received just one dose throughout the study. The timing of its administration was not related to the duration of the study, although full "top-up" doses were often given during transition into second stage or for unilateral block. The number of full "top-ups" did not vary among groups. Out of 68 patients, a total of 13 full "topup" supplements were given (19\%), with a range of 1-4 full "top-ups" across groups. 
TABLE III Motor weakness

\begin{tabular}{|c|c|c|c|c|c|}
\hline $\begin{array}{l}\text { Degree of weakness } \\
\text { (\# patients) }\end{array}$ & $\begin{array}{l}A \\
n=14\end{array}$ & $\begin{array}{l}B \\
n=14\end{array}$ & $\begin{array}{l}C \\
n=13\end{array}$ & $\begin{array}{l}D \\
n=14\end{array}$ & $\begin{array}{l}E \\
n=13\end{array}$ \\
\hline None & 12 & 11 & 8 & 8 & 6 \\
\hline Weak hip flexion but able to flex knee & 1 & 3 & 3 & 5 & 4 \\
\hline Unable to flex hip, just able to flex knee & 1 & 0 & 2 & 1 & 3 \\
\hline Unable to flex knee & 0 & 0 & 0 & 0 & 0 \\
\hline
\end{tabular}

$P=$ NS

TABLE IV (a) Percentage of patients requiring extra epidural supplements by anaesthetist

\begin{tabular}{llllll}
\hline Supplement & $A$ & $B$ & $C$ & $D$ & $E$ \\
\hline Bupivacaine (B) (\%) & 35.7 & 14.3 & 35.7 & 21.4 & 28.6 \\
Fentanyl (F) (\%) & 28.6 & 28.6 & 14.3 & 21.4 & 14.3 \\
Either (B or F) (\%) & 50.0 & 28.6 & 42.9 & 35.7 & 28.6 \\
\hline
\end{tabular}

$P=$ NS

TABLE IV (b) Number of supplemental doses given per group

\begin{tabular}{llllll}
\hline Supplement & Group A & Group B & Group C & Group D & Group E \\
\hline Bupivacaine/(\% full top-ups) & $8 /(50 \%)$ & $3 /(66 \%)$ & $5 /(40 \%)$ & $3 /(33 \%)$ & $5 /(80 \%)$ \\
Fentanyl $(n)$ & 7 & 6 & 2 & 3 & 3 \\
\hline
\end{tabular}

$P=$ NS (full top-up is $12 \mathrm{ml}$ of $0.125 \%$ bupivacaine with $1: 800,000$ epinephrine)

TABLE V Delivery type and neonatal outcome

\begin{tabular}{llllll}
\hline Group & $\begin{array}{l}A \\
(n=13)\end{array}$ & $\begin{array}{l}B \\
(n=14)\end{array}$ & $\begin{array}{l}C \\
(n=13)\end{array}$ & $\begin{array}{l}D \\
(n=14)\end{array}$ & $\begin{array}{l}E \\
(n=13)\end{array}$ \\
\hline $\begin{array}{l}\text { Spontaneous vaginal delivery } \\
\text { Ventouse assisted }\end{array}$ & 8 & 6 & 4 & 7 & $3^{*}$ \\
$\begin{array}{l}\text { Forceps delivery } \\
\text { Caesarean birth }\end{array}$ & 1 & 1 & 1 & 0 & 0 \\
Apgar score (\# babies) with & 2 & 3 & 6 & 5 & 6 \\
$\quad 2$ & 4 & 2 & 2 & 4 \\
$\quad<7$ at 1 min & 1 & 3 & 4 & 3 & 1 \\
$\quad \begin{array}{l}\text { Resuscitation required } \\
\text { Res min }\end{array}$ & 0 & 0 & 0 & 0 & 0 \\
\hline
\end{tabular}

${ }^{*} P<0.05$ for difference between Group E and all PCEA groups combined.

Delivery type and neonatal outcome are described in Table V. The spontaneous vaginal delivery rate was less in Group E than Groups A-D combined, $21 \%$ vs $51 \%$, $(P<0.5$, Chi-square).

Three neonates required resuscitation at birth for low Apgar scores and meconium present at delivery. All were easily treated, using suction below the cords and IPPV with $100 \%$ oxygen for $30-60$ secs. Each had a good outcome with normal five minute Apgar scores. There was no correlation between low one minute Apgar scores and umbilical artery fentanyl concentrations (all were $<0.1$ $\mathrm{ng} \cdot \mathrm{ml}^{-1}$ ).

No patient had a fentanyl concentration $>0.5 \mathrm{ng} \cdot \mathrm{ml}^{-1}$ in maternal or umbilical samples and there was no cor- relation between total fentanyl consumption or time of last fentanyl dose and the plasma concentration. Seventy percent of all samples had a fentanyl concentration $<0.1$ $\mathrm{ng} \cdot \mathrm{ml}^{-1}$ and there were no differences in plasma fentanyl concentrations among groups.

After completion of the study both patient and investigator evaluated efficacy of the technique using a five point scale (poor, fair, good, very good, excellent). All evaluations were rated good to excellent with no difference among groups.

\section{Discussion}

This study asked the following questions: (1) Does it matter which PCA dose variables are used to set up PCEA 
in labour? (2) Is PCEA, without a background infusion, as effective as CIEA?

The results showed no differences among any of the PCEA groups, except that Group D patients, who received the largest bolus size with each patient administration, had higher sensory levels than the others at three and four hours into the study. No adverse sequelae were seen, such as maternal hypotension or fetal bradycardia, as a result of this observed difference. In addition, the incidence of motor block was similar in all four PCEA groups.

The number of analgesic supplements of either epidural fentanyl or bupivacaine was the same in all four groups. The percentage of patients receiving either a bupivacaine or fentanyl supplement ranged from a high of $50 \%$ in Group A to a low of $28.6 \%$ in Group B ( $P=$ NS); see Table IV. Overall, $37 \%$ of all parturients receiving PCEA required additional supplementary boluses, which is comparable with the $34 \%$ reported by Paech in a previous study. ${ }^{5}$

If every PCA demand had resulted in successful administration then the success:total ratio would be 1.0. In Group A this ratio was highest at 0.64 and in Group D lowest at $0.41(P=\mathrm{NS})$. This ratio may not only reflect efficacy of the combination of dose variables, but also differences in the way PCA is used by parturients. Some press the demand button at the slightest provocation while others make only a few demands each hour. In the long run, patients are satisfied with the technique irrespective of their pattern of PCA use.

All PCEA groups experienced the same degree of analgesia and satisfaction, with comparable bupivacaine and fentanyl consumption. Patients in Group E, however, used more bupivacaine and fentanyl throughout the study than Groups A-D, alone or in combination. This finding is in keeping with other reports which have shown that PCEA is associated with a dose-sparing effect compared to continuous epidural infusion. $2,4,5$ This finding is even more pronounced when there is no background or basal infusion used with PCEA. Our results have shown that bolus-only PCEA is as effective as CIEA, with $45 \%$ less bupivacaine and $36 \%$ less fentanyl consumption in the PCEA groups combined. The redundancy of a background infusion with PCEA has also been shown in studies by Ferrante ${ }^{4}$ and Paech. ${ }^{5}$ Ferrante demonstrated a $47 \%$ dose-sparing of bupivacaine and a $55 \%$ sparing of fentanyl when "demand-dosing" PCEA was compared to CIEA. Paech showed a dose-sparing of fentanyl, but not bupivacaine, in those patients receiving PCEA without a basal infusion. Degree of analgesia, maternal satisfaction and side effects were similarly unaffected by the addition of a basal infusion. Similar conclusions were made in another study, which compared bolus-only PCEA with intermittent "top-up" injections by an anaesthetist. ${ }^{6}$ Each of these reports confirm the study by Owen et al. who administered intravenous PCA with a concurrent infusion. ${ }^{7}$ An arbitrarily selected basal rate, over which the patient has no control, compromises the theoretical advantages of PCA. The patient can no longer tailor the administration of analgesia to her needs, because of an additional factor over which she has no control. This is particularly important with the $i v$ technique because insidious opioid overdose is possible in some patients. Owen summed it up by stating that "... addition of mandatory infusion to PCA not only fails to improve the efficacy but it also reduces (its) inherent safety ...".?

Our present study has shown that CIEA, using bupivacaine $0.125 \%$ with epinephrine and fentanyl, was associated with a lower rate of spontaneous vaginal delivery (SVD) than all PCEA groups combined. This has not been observed in other studies. There are many factors which can affect SVD rate but cannot be controlled. Our observation does not imply a cause and effect relationship between CIEA and lower rates of SVD. A study with larger numbers would be needed to confirm this finding.

High patient satisfaction was reported by most patients in this study either by VAS scores or by the global evaluation completed at the end of the study. Group E patients were no different. This may have been due to the double-blind nature of the study and the intrinsic placebo effect of PCEA. ${ }^{2}$ Previous studies of PCEA have also demonstrated high patient acceptance and satisfaction, making this technique an increasingly popular method of labour analgesia. ${ }^{8-11}$

Whereas we did not study the effect of PCEA during the second stage of labour, in practice most parturients using PCEA are advised to self-administer doses throughout the second stage. This is in contrast to the usual practice of many birth attendants, who are reluctant to give further doses during the second stage, out of concern for prolonging its course and increasing the risk of instrumental delivery. Ferrante demonstrated that second stage use of PCEA did not adversely influence delivery. There was a $90 \%$ SVD rate in his study. ${ }^{4}$

Patient-controlled epidural analgesia provides a means of comparing one local anaesthetic with another, in various concentrations with or without different opioid supplements. The addition of fentanyl $2.5 \mu \mathrm{g} \cdot \mathrm{ml}^{-1}$ to bupivacaine $0.125 \%$ with $1: 400,000$ epinephrine resulted in measurable levels of fentanyl in the plasma of some samples. No patient suffered sequelae from fentanyl apart from mild pruritus. All fentanyl concentrations were $\leq 0.5$ $\mathrm{ng} \cdot \mathrm{ml}^{-1}$, corresponding to the lower levels of the minimum effective analgesic concentration (MEAC) for fentanyl. ${ }^{12}$ Respiratory depression in the neonate is usu- 
ally associated with a plasma fentanyl concentration $>1.0$ $\mathrm{ng} \cdot \mathrm{ml}^{-1}$. $^{13}$

Another method by which we might have assessed PCEA variables is to alter dose volume while keeping lockout time constant. Alternatively the lockout time can be varied using a constant dose volume. Although we considered these options, we elected to allow parturients access to a guaranteed maximum hourly volume through the PCA pump. In a recent study by Purdie et al., ${ }^{10}$ the parturient had access to all doses in the first $20 \mathrm{~min}$ rather than spacing the doses evenly throughout the hour (e.g., $4 \mathrm{ml}$ dose q $5 \mathrm{~min}$ with an hourly maximum of $16 \mathrm{ml}$ ). Past studies have used evenly spaced doses. A future study of these two dosing patterns might shed light on which is superior.

In summary, there were no differences seen among the four dosing programmes chosen for PCEA in labour. Patients in each group experienced similar degrees of satisfactory pain relief, and this was comparable to the analgesia provided by constant infusion. All PCEA groups had lower bupivacaine and fentanyl consumption than with continuous infusion. The PCEA was associated with a higher spontaneous delivery rate than CIEA, but management of second stage of labour was not standardized. No parturient or newborn had a clinically important serum fentanyl concentration. Bolus-only PCEA using bupivacaine $0.125 \%$ with $1: 400,000$ epinephrine and fentanyl $2.5 \mu \mathrm{g} \cdot \mathrm{ml}^{-1}$ is a safe and effective technique regardless of which initial dose and lockout interval is programmed. Reasonable hourly maximum doses should not be exceeded and minimum effective hourly doses should be guaranteed.

\section{References}

1 Egan KJ. What does it mean to be in "control"? In: Ferrante FM, Ostheimer GW, Covino BG (Eds.). PatientControlled Analgesia. Boston: Blackwell Scientific, 1990: 17-26.

2 Gambling DR, Yu P, Cole C, McMorland GH, Palmer L. A comparative study of patient controlled epidural analgesia (PCEA) and continuous infusion epidural analgesia (CIEA) during labour. Can J Anaesth 1988; 35: 249-54.

3 Lysak SZ, Eisenach JC, Dobson CE 2nd. Patientcontrolled epidural analgesia during labour: a comparison of three solutions with a continuous infusion control. Anesthesiology 1990; 72: 44-9.

4 Ferrante FM, Lu L, Jamison SB, Datta S. Patientcontrolled epidural analgesia: demand dosing. Anesth Analg 1991; 73: 547-52.

5 Paech MJ. Patient-controlled epidural analgesia in labour - is a continuous infusion of benefit? Anaesth Intensive Care 1992; 20: 15-20.

6 Gambling DR, McMorland GH, Yu P, Laszlo C.
Comparison of patient-controlled epidural analgesia and intermittent "top-up" injections during labour. Anesth Analg 1990; 70: 256-61.

7 Owen H, Szekely SM, Plummer JL, Cushnie JM, Mather $L E$. Variables of patient-controlled analgesia. 2. Concurrent infusion. Anaesthesia 1989; 44: 11-3.

8 Paech $M$. Epidural analgesia in labour: constant infusion plus patient-controlled boluses. Anaesth Intensive Care 1991; 19: 32-9.

9 Celleno D, Capogna G, Costantino P, Sebastiani $M, M u-$ ratori $F$, Cipriani $G$. A comparison between top-up doses, continuous epidural infusion and patient controlled epidu$\mathrm{ral}$ analgesia for labour with $0.125 \%$ bupivacaine with or without fentanyl (Abstract). Reg Anesth 1991; 15 (1S): 37.

10 Purdie J, Reid J, Thorburn J, Asbury AJ. Continuous epidural analgesia: comparison of midwife top-ups, continuous infusions and patient-controlled epidural administration. Br J Anaesth 1992; 68: 580-4.

11 Viscomi C, Eisenach JC. Patient-controlled epidural analgesia during labor. Obstet Gynecol 1991; 77: 348-51.

12 Gourlay GK, Kowalski SR, Plummer JL, Cousins MJ, Armstrong PJ. Fentanyl blood concentration - analgesic response relationship in the treatment of postoperative pain. Anesth Analg 1988; 67: 329-37.

13 Hertzka GK, Gauntlett IS, Fisher DM, Spellman MJ. Fentanyl induced ventilatory depression: effects of age. Anesthesiolgy 1989; 70: 213-8. 